\title{
Modified Film Form in Reference to Contextual 3-D Filmmaking: Challenging the Monopoly of Film Form and Dissemination of Knowledge in Indonesia
}

\author{
Tunggul Banjaransari ${ }^{\mathrm{a}, 1, *}$ \\ ${ }^{a}$ D4 Film and Television Major, Dian Nuswantoro University, Semarang Indonesia \\ 1 tunggul_cross@yahoo.co.id \\ * corresponding author
}

\section{ARTICLE INFO}

Article history

Received 2019-05-02

Revised 2019-05-04

Accepted 2019-05-22

Keywords

Film Distribution Monopoly

Film Form Monopoly

Adaptation on 3-D Technology

\section{ABSTRACT}

The variety of films distributed in Indonesia are homogenous, which profoundly impacts the dissemination of knowledge generated by the movie. Since the information exposed to the public derived from one single source, it is highly potential to politicize the distribution of society's collective knowledge - for instance, the arrangement on film circulation. Indonesian Censorship Institute does not only authorized the quantity of the film circulated in the country but also regulates the quality of the movie itself. Films that contain any ideological deviation, moral standards digression, and disobedience to the State will surely be banned. Inevitably, the flow of capital for filmmaking shall follow the State's standard of circulation. The flourishment of the Indonesian community-based independent film screenings network simultaneously provides an alternative source of information to society. Such knowledge - regarded by the State as the Other-is vital since the enormous scope of knowledge is inaccessible as a result of the State's limitation. The film communities dedicate alternative screenings as a space for the audience to explore various kinds of films with different knowledge. The researcher experimented with combining the situation of the society constrained by the State with the adaptation of 3-D filmmaking. The adjustment is manifested in the utilization of layerednarrative as an effort to illustrate the role of information obtained from various sources. The experiment is expected to encourage the audience to gain knowledge as if they were putting the pieces of the film scenes into a puzzle.

This is an open-access article under the CC-BY-SA license.

\section{Introduction}

This article serves as a note of the process of making a short film titled Udhar. The report covers the background of the film, its theoretical framework, as well as the method used in the making of the film. There are two underlying problems behind the making of Udhar. Firstly, Udhar highlights the issues of the dominant film form as well as the pattern produced and circulated in Indonesia. Indonesian film form can be considered as politicized, resulting in the homogenous products generated in the country's film industry. The condition is due to the interest of certain parties with capital power, driving the filmmakers to depend on the flow of the funding and simultaneously pushing them to agree with the dominant interest, putting aside their ideology, personal vision, and art exploration [1]. It is then affected the community as the audience since they are given similar films each year. The condition is regarded as ironic since cinema is the most active community's literacy media amid the State-censorship policy over the dissemination of knowledge and information channels [2]. 
If the circulated films are homogenous products, it can be concluded that there is only a single source of knowledge, specifically derived from the State's perspective. The audience is given a comprehensive source of information, which holds a considerably great potential to politicize the information out in public [3]. It shows that film production is no longer serves as an internal problem; it is intertwined with the broader society. It was evident that film is densely influenced by the politics of the economic interest, which only put greater discourage on the country's film development.

The elaboration above raises the second problem questioned in this research regarding the politicized film circulation system that intertwined with the dissemination of knowledge among society. The State's Censorship Institute plays an essential role as the State apparatus that responsible for managing the film form to the extent of the distribution stage [4]. If the content and context are counterproductive with the State's interest, most likely, the film will be banned. The criteria itself is also worth to be questioned since the State tends to confuse religion and separate the film as a commodity [2]. For example, sexual content is highly restricted due to its potential to bring bad influence on the young generation. Does sexual content can only be viewed solely on the moral side? Or is it banned because it brings no substantial knowledge? Good reason becomes the only explanation given to the public, which pushes the State to take extreme action, allowing the government to intervene in human's private business, specifically regarding the matter of sexuality [5].

The issues mentioned above encourage the researcher to experiment with the making of Udhar. The filmmaking is based on the exploration of film form, especially on the layered-narrative in a single scene. The utilization of layered-narrative represents the depiction of knowledge derived from several sources, supported by the film's design characters, design sound, and the movement of the scenes. It is expected that the method can encourage the audience to dig various information by putting the 'puzzle' of each scene to comprehend the meaning of the film. As mentioned earlier, the film will present a kind of game for the audience as if they were arranging a puzzle from every layer of the story to reach their interpretation and meaning.

\section{Constructive Methodology: 3-D Filmmaking Adaptation}

The making of Udhar utilized a productive methodology. According to Denzim, constructivism is a methodology used to elucidate a subject matter [6][7]. The useful method is developed from hermeneutics; the difference lies upon its subjective interpretation of various elements of the text to find a contextual explanation of the problem [6][8]. The making of Udhar does not solely posit the aspects of film such as narrative, camera works, editing pattern, film tempo as a set of texts but also makes use of the film production's extrinsic elements embodied in the working principle of the 3-D film.

Films in 3-D format offer a different experience than the conventional ones. 3-D technology can simultaneously present three distinct areas that operate in separate spaces but still use the same media. In this sense, the media refers to the screen, but with 3-D technology, the film moves as if some objects are present out of the screen. Until 2016, 3-D films can be enjoyed using glasses designated for the technology. If one is watching it without any assistive aid, the areas on the screen will be blurred. The lenses are meant to unite the regions into one point of focus, resulting in poking the objects out of the screen.

In Indonesia, 3-D technology has been available since the beginning of the 1990s. In addition to several TV serials, Keong Mas theatre in Taman Mini Indonesia Indah has already applied the technology. After 2005, 3-D films have yet again gained popularity among the Indonesians. Moreover, the technology of the camera, as well as image and sound projectors, have already adopted the DCP (Digital Camera Package) format with laser projection higher than the projector's lumens capacity. The advancement in projector technology-enabled 3-D films to come out as close and real as it can be. 3-D movies are produced - in general - by Hollywood film industry, more specifically in action, superheroes, and horror films, to name a few. With the ability to create proximity between the audience and the events that happened in the movie, 3-D films inevitably offer a new experience to its audience. 
Several 3-D films were produced by Indonesians as well, although the movie failed to gather many audiences. From the perspective of technical production, 3-D films required meticulous arrangements on each frame of the scene while also demanded a profoundly large amount of money. The camera setting applied the primary colors in photo imaging, the RGB (Red Green Blue) format, is set in a different arrangement. In a single scene, the RGB format is initially set in conventional ways. Meanwhile, in the second shoot, the RGB format is set in a different color-either the red color level is increased or decreased. The arrangement is used to enable the 3-D glasses to receive two different primary colors.

The color variability generated the objects as if they are poked out of the screen. Such results work by the support from the glasses. The glasses itself are designed with different lens functions, the red lens on the left side, and the blue one on the other side. The color difference is used to disengage the primary RGB colors presented on the screen. The red lens will refuse green colors, which also works on the opposite; green colors will refuse red ones. In other words, each of the human's eye functions differently than the other one. The color extrication is then received by the brain, which projected the area as if they are coming out of the frame since one object generates two areas extricated by the necessary colors. The division of the regions is categorized by colors but unites by the human brain. Nevertheless, it should be noted that the whole work of 3-D technology disables people with colorblind or half-blind to enjoy 3-D films.

It is undeniable that 3-D films offer a different experience to the audience. The technology also provides filmmakers with a vast space of exploration in bringing a new dimension in experiencing a movie. However, the technology holds particular problems. Besides, it requires a considerably large amount of money; 3-D films cannot facilitate people with colorblind or half-blind. It further encourages the researcher to dig deeper into the technology of 3-D films by applying it using manual principals. In other words, the film will not generate objects that poked out of the screen. The dimensions will be constructed from the elements connected to the audience. Therefore, a sense of proximity will be created among the audience without having to produce objects in 3-D format. The materials that determined the dimensions will be explained in the following chapter.

\section{Results and Discussion}

\subsection{Analysis of Tiled Large-Screen on Film Using Parallax Reality}

In initiating the breakdown process of the materials needed in the making of Udhar, the researcher utilized the parallax view as the concept of the model analysis to create the original content for the film. The parallax view is a concept coined by Slavoj Zizek. The word 'parallax' is usually used in physics studies, which refers to the apparent displacement of an object caused by a change in an observational position [9]. Zizek is known to often use natural science terms. Parallax indicates the shifted function of an object - to the extent that the original purpose is displaced-by altering the background without moving the object. The condition happens due to the change in the different observant' positions in viewing the object [10]. Zizek continued to give the context regarding the potential power that occurred mainly in changing the perspective of seeing an object. According to him, the change of position can be unified through a specific angle that encompasses the entire human's perspective. The concept of parallax is considered as relevant to the activity of watching a film.

During a film screening - whether screened in a theater, TV set, or laptop/PC - the audience is being 'lent' a pair of glass during the process of acquiring the information provided by the film. For instance, in looking at a scene showing the National Monument (Monas), we are only given the depiction of the magnificent view over the monument. In the film, we cannot access the other side of the memorial, the ones that absent, hidden by the film. A similar phenomenon happens in Hollywood action films as well. We are only given the perspective of how powerful the main character is in dealing with the conflict. There is not a single chance for the audience to recognize the character's weaknesses. The audience is being guided to be close with the main character, even defending the cause advocated within the story to the degree of sparking the audience's sympathy towards the main character. In this condition, human - the audience - is shifted into a passive subject, persuaded to voluntarily follow the written agendas on the screen. 
The audience's passive condition is - in fact-ironic, as explained by Zizek, that it can be manipulated by the authority to drive humans further into the chain of capitalism even though humans are allowed to have their perspective over an object. However, the interaction between film and its audience is the intersection of various realities; the audience's existence, the filmmaker's presence, as well as the reality surrounded the screening space. The intersection ought to flourish discourse since there is no such thing as 'passive subject.' The most dominant subject-in this case - is the filmmaker's reality, supported by the technology that blurred the audience's reality and plunged them into a state of relaxation. According to Zizek, it is possible to bring an adverse effect, but it is also possible to bring a positive impact when the audience requires relaxation. To illustrate further, the process that happens during the event of watching a film is elaborated in figure 1.

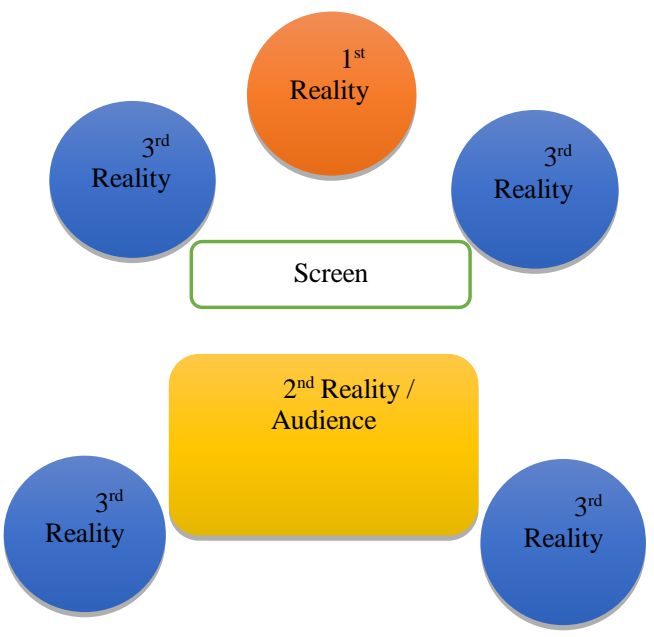

Fig. 1. The Process that Happens During the Event of Watching a Film

The explanation of figure 1 shows that 1st reality refers to the filmmaker's fact reflected in the film. 2nd Reality refers to the audience's reality in giving a response to the film. 3rd Reality refers to the reality that happened outside the screening space, comprising various kinds of fact depends on the geographical and cultural context. It can also be rendered as a reality in a broader sense. For example, in the existence of Indonesian films in 2018 or put, within the area of screening space, there might be eight people who do not know that the room functions as a screening space. Screen refers to the media of the intersection of reality - a meeting point between the filmmaker's and the audience's fact - which generates a discourse between two parties. It should be noted that, as explained by Zizek, in the case of Hollywood films, the screen does not serve as the mediator between the maker and the audience [10]. It functions as an 'entry door' as well as a 'trap door' that limits the audience's interpretation and imagination.

The breakdown of the parallax concept adopted into the process of watching a film resulted in three dimensions, which then developed and cultivated as the materials in making Udhar. The aspects will create its layer on the frame of the scenes that represent each reality. The mechanism of the three layers in the scenes are similar to the tool of 3-D film format. Nevertheless, Udhar will not present as a short film in 3-D format, but more on the narrative layers and spaces are shown in the movie. The universe is thus an invisible and unified whole, in which all the dual oppositions (light vs. darkness, being vs. non-being, cinema vs. non-cinema) are not ontological absolutes but the results of decisions through which humans construct their being in the world [11]. Udhar is going to expand the cinema which looks non-cinema. Non-cinema becomes a thus relevant concept that enables us to explore a world of invisibility and indivisibility, which is beyond the scope of cinemacapital.

\subsection{Synchronization of 3-D Film Format in Film Form and Audience's Geo-Cultural Context}

Based on the three dimensions elaborated in the previous chapter, the process continued to the stage of connecting the fragmented aspects. The researcher connects the dimensions through the narrative constructed based on the filmmaker's reality as the first reality while the second and third reality function to frame the space. The aspect of the area is divided into two spaces to represent the particular condition of the society (for example, the status of Indonesian middle-class residence) and 
space constructed on the actual problems happening among the community. The division marks as the strategy to give the audience a clue/sign to open the sense of proximity with the conflicts narrated in the story. The division in the aspect of space is based on the duration needed for the film's progress manifested in the story and space [12]. A period is a fundamental element that forms a film and differs from other visual arts (photography, design, or other skills form using the moving image media). One of the strategies to progress the duration is through the narrative and sequence of scenes that needed space or blocking [12].

In this study, the details are explained as follows, $1^{\text {st }}$ Reality serves as the narrative that represents the filmmaker's intention in telling the story/elaborating particular opinions through the film. The description generates the main character, secondary characters, the sequence of the scenes, and the plot of the story. $2^{\text {nd }}$ Reality embodied in a condition/main topic consumed by society through mass media. The researcher takes religion as the film's topic. The objective of the subject aimed at opening the door for the audience to feel the proximity through the overall dimension presented in the movie. The other reality manifested in the conflicts that surrounded the main character of the film. $3^{\text {rd }}$ Reality is realized as space within the film. Udhar takes native Solo middle-class society as a sample. It is accurately depicted through the rooms within the house that captured as a dense space, blurring the borders of the bedroom, dining room, and the family room. Piles of boxes and magazines are scattered. This aspect generates a space for the main character and the secondary ones to play the roles as the factors that drive the story, supported by locations, artistic, and blocking arrangement as well.

The film screen represents the amalgamation of several functions. It serves as the two-way communication media (between the filmmaker and the audience) and the projectors of the unreal, but it still can be seen by others. The amalgamation is meant to encourage the audience to access the diverse dynamics in watching a film. For example, in one scene, the audience might perceive that the film falls under the classification of 'imaginative.' On the other views, 'the imaginative' within the film is talking to them, opening an interactive relationship. Lastly, in some scenes, the audience is the ones who intervene in the main character. These aspects resulted in the scenes that reflect the communication happens between the film and the audience through the embodiment of characters, their interactions with the audience, and the tiled large screen that framed the film.

After putting the three dimensions and adding the screen to support the film duration, the next step is writing the screenplay. The screenplay functions as guidance during the film production process. The film, titled Udhar, derives from one of the stages in the Javanese music ensemble (Karawitan). In the scene, Udhar does not suppose to stand alone, and it presents as the binary opposition to Sirep. Both stages should be present hand-in-hand in a song during a performance. Both elements reflect two different things but simultaneously cannot be separated from one another. Sirep refers to a stage in which the Javanese instruments produce silence rhythm, bonds, and bring the listeners to a calm condition, trigger them to let go of the burdens of life while Udhar refers to a stage that encourages the listeners to stay alert, aware that they have to live their reality. The researcher decided to use Udhar to represent the concept of parallax, denoting the human condition that plunged into their deepest fantasy, which enabled them to be easily controlled by the system of capitalism.

\subsection{Udhar: the Discourse Generates by the Film}

Abbas Kiarostami once stated that a film fulfills itself when it screened in front of other people, not only enjoyed by the filmmaker [13]. Udhar is tested in several screening programs and places, both in the national and international film festival circuit and non-profit theaters. The screenings list are as follows (1) Bangkok International Short Film Festival; (2) Seashore Kuala Lumpur Film Festival; (3) Jogja-NETPAC Asian Film Festival; (4) Festival Film Solo (Solo Film Festival); (5) Ganesha Film Festival; (6) Singapore International Film Festival; (7) Kineforum theater, Jakarta Arts Council; (8) Bioskop Jumat, Palu.

The film generates various discourse, one of which stated by Eric Sasono, who explained that the works produced by the researcher, including Udhar, are the works that changed the film position from a sacred place into a comical one. Eric uses the analogy of the same effort taken by Roy Anderson (a Swedish filmmaker who is active from the 1990s to the present) in using satire technique applied in his works to challenge Ingmar Bergman's (a Swedish filmmaker who was active from 1950s to 1990s) bleak film language. The researcher is dubbed as the Indonesian Roy 
Anderson, who shifted the bleak, restricted, and full of philosophy film language as applied by Sjumandjaja and Asrul Sani. The researcher is considered to present films as if they were an Indonesian comedy show, Srimulat, and put it as something that accessible and understandable to the audience. Comical movies are essential to broaden the knowledge of the film itself in the effort to avoid being identified with the incomprehensible and serious cinema.

Mikael Johani, in his curatorial note in Festival Film Solo, mentioned that Udhar, at some points, takes the reference of Gummo and Losmen at the other end. The film is so talkative, similar to Robert Altman's, but the same movie also takes the audience in a graveyard. The audience is brought back and forth from Javanese culture to the influence of global capitalization. Writing the note for the same program, Adrian Jonathan Pasaribu stated that Udhar brilliantly puts the phenomenon of religiosity in a playful film framing, the researcher thoroughly used the tiled large screen to prioritize which ones should be highlighted and which ones should be hidden but still can be accessed by the audience [14].

Besides being screened in places mentioned above, Udhar also achieved an accolade as Asia Best Short Film. The award was presented by NETPAC (Network for Promotion of Asian and AsiaPacific Cinema) - an association that provides a space for Asian filmmakers to bring their works to the global audience. The recognition is awarded since the film can bring a breakthrough in world cinema through a practical experiment. Additionally, the film also listed in Indonesian 10 Best Films released by Cinemapoetica [15]. The appreciation and discourse generated by the film have opened, even triggered, the habit of watching movies among society. Not only serve as entertainment, but movies can also serve as the media of literacy [16]. Therefore, the emergence of a similar space can actively contribute to the development of film exploration - the objective of the investigation aimed at finding new possibilities in the film form and film context.

\section{Conclusion}

3-D film stipulates the achievement in the technology of filmmaking in enabling the audience to experience movies in a new way. 3-D films are dominantly produced in Hollywood. In general, 3-D films are often found in action, superheroes, horror, and thriller films, to name a few. Hollywood film industry is not the sole producer of 3-D cinema. Some non-U.S film companies also applied the same technology to provide new experience and proximity to the films. Some films in Indonesia have even implemented technology. The process of adoption can be considered a compelling case since it means that the non-U.S film industry can produce its films using the method. It also signifies that Hollywood is no longer the dominant player in the sense of capital ownership and application of the updated film technology among other film industry players. However, a question should be raised whether there are any differences made between Hollywood 3-D films and the other industries, including Indonesia. If discrepancies are nowhere to be found-whether in the technology, film form, and audience-experience orientation - the audience will likely prefer to choose the authentic ones (Hollywood's) rather than the other industries'. Then, how to effectively adopt the technology and simultaneously avoid the domination of Hollywood's 3-D films?

Based on the problems, the researcher started to breakdown several materials to construct a 3-D film that represents a particular cultural condition. In the breakdown process, the researcher used the concept of a parallax view. The idea has been used in physics studies to explain the apparent displacement of an object caused by a change in observational position. Slavoj Zizek uses a parallax view to explain the relationship between film and its audience, which has been capitalized by the arrangement of sequences manifested in the movie by the maker. In short, when watching a film, the audience is being 'lent' with the filmmaker's glasses to explore anything the film presents. The lenses are made to have adverse effects on the audience, which put them into a group of ignorant people in need of the filmmaker's glasses to see the film's perspective. Such results hold a significant potential to capitalize on the audience. The researcher then broke down into three variables regarding the process of watching a film. The variables are comprising of different realities, the first reality refers to the filmmaker's, the second one refers to the audience's face, and the third one refers to the fact surrounding the screening space.

Furthermore, the variables served as the necessary materials to develop a film form that generates a film with a 3-dimensional frame. The difference between the film produced by the researcher and 3-D film in general highlighted on the audience's memory that drives them into proximity through 
the spaces presented by the filmmaker. It proves to affect the close relationship between the film and the audience, dissolving the distance without having to put the filmmaker's glasses on the audience. It resulted in the dissemination of various interpretations according to the memory, experience, proximity between the audience and the character constructed by the film. In other words, Udhar successfully generated an interactive relationship with its audience.

\section{References}

[1] E. Imanjaya, E. Sasono, and H. Darmawan, Menjegal Film Indonesia: Pemetaan Ekonomi Politik Industri Film Indonesia. Jakarta: Tifa Foundation, 2011.

[2] K. Heeren van, "Contemporary Indonesian Film; Spirits of Reform and ghosts from the past," Contemp. Indonesia. Film. Spirits Reform ghosts from past, 2012.

[3] T. Elsaesser, "ImperSonations: National Cinema, Historical Imaginaries, and New Cinema Europe," Mise Au Point, vol. 5, 2013.

[4] K. Sen, D. H. Suwarto, and K. Adi, Sinema Indonesia: Membingkai Orde Baru. Yogyakarta: Rumah Sinema, 2013.

[5] K. G. Cheng and T. Barker, Mau Dibawa Kemana Sinema Kita Beberapa Wacana Seputar Film Indonesia. Jakarta: Salemba Humanika, 2011.

[6] N. K. Denzim and L. Y. S., Handbook of Qualitative Research. Yogyakarta: Pustaka Pelajar, 2009.

[7] K. Yilmaz, "Constructivism: Its Theoretical Underpinnings, Variations, and Implications for Classroom Instruction," Educ. horizons, vol. 86, no. 3, pp. 161-172, 2008.

[8] T. A. Schwandt and others, "Constructivist, Interpretivist Approach to Human Inquiry," Handb. Qual. Res., vol. 1, pp. 118-137, 1994.

[9] S. Zizek, The Parallax View. Massachusetts: The MIT Press, 2009.

[10] M. Flisfeder, The symbolic, the sublime, and Slavoj Žižek's theory of film. 2016.

[11]F. Brayard, "Non-Cinema: Global Digital Film-making and The Multitude," Screen, vol. 60, no. Sarah Street, p. 369, 2019.

[12]D. Bordwell and K. Thompson, Film Art: An Introduction. 2001.

[13] J. Akrami, A Walk With Kiarostami. USA, 2003.

[14]M. Johani, A. J. Pasaribu, and M. Mubarak, “Katalog Festival Film 2014,” 2014.

[15] A. J. Pasaribu, "Sepuluh Film Indonesia Pilihan Tahun 2014,” 2015.

[16] J. Kristanto, Nonton Film Nonton Indonesia. Jakarta: Penerbit Buku Kompas, 2004. 